\title{
Young children's imagination in science education and education for sustainability
}

\author{
Cecilia Caiman' ${ }^{1}$ Iann Lundegård ${ }^{1}$
}

Received: 24 June 2014/ Accepted: 17 March 2017/Published online: 19 September 2017

(C) The Author(s) 2017. This article is an open access publication

\begin{abstract}
This research is concerned with how children's processes of imagination, situated in cultural and social practices, come into play when they invent, anticipate, and explore a problem that is important to them. To enhance our understanding of young children's learning and meaning-making related to science and sustainability, research that investigates children's use of imagination is valuable. The specific aim of this paper is to empirically scrutinize how children's imaginations emerge, develop, and impact their experiences in science. We approach imagination as a situated, open, and unscripted act that emerges within transactions. This empirical study was conducted in a Swedish preschool, and the data was collected 'in between' a science inquiry activity and lunchtime. We gathered specific video-sequences wherein the children, lived through the process of imagination, invented a problem together and produced something new. Our analysis showed that imagination has a great significance when children provide different solutions which may be useful in the future to sustainability-related problems. If the purpose of an educational experience in some way supports children's imaginative flow, then practicing an open, listening approach becomes vital. Thus, by encouraging children to explore their concerns and questions related to sustainability issues more thoroughly without incautious recommendations or suggestions from adults, the process of imagination might flourish.
\end{abstract}

Keywords Imagination $\cdot$ Meaning making $\cdot$ Sustainability $\cdot$ Science

Lead editor: G. Glasson

Cecilia Caiman

cecilia.caiman@mnd.su.se

1 Department of Mathematics and Science Education, Stockholm University, Stockholm, Sweden 


\section{Imagination in education for sustainability}

Imagination is defined as the creative ability to form ideas and images without immediate, external sensory input (Egan 1992). It broadens and deepens human experience by seeing familiar objects in a new light (Dewey 1934/1980) and helps to make knowledge applicable in solving problems. Therefore, imagination is fundamental to integrating experience in the learning process and has been treated as an indispensable precondition for helping humanity to tackle multi-complex problems and create innovations (Sandri 2013). Energy systems and advancements in waste management and transportation have, for example, been developed through novel ideas (Editorial board of IJDCI 2013). Education for sustainability requires thinking and acting in ways that will safeguard the future wellbeing of people, species, and our planet (Davis 2010).

Some argue that the breadth of environmental devastation we might face in the future is even beyond our imagination (Blenkinsop and Egan 2009). In these living conditions where increasing biodiversity loss and social and ecological crisis are a reality (Sauvé 2009), there is unquestionably a need for new ideas on how to address these multifarious problems (Churchman 1967; Harvey and Pilgrim 2011). These problems are often unstructured, cross-cut through several structures, and present a range of contradictory options on how to live our lives (Weber and Khademian 2008). This is indeed relevant when particularly addressing sustainability issues (Sandri 2013), due to the fact that they simultaneously address economical, social, and ecological dimensions. Therefore, one of our largest educational challenges is to help younger generations to "cope creatively with the unavoidable uncertainty" (van Eijck and Roth 2013, p. 210).

\section{The power of children's imagination}

The need to support unusual and unique questions and concerns posed by children has been highlighted in the fields of Environmental Education/Education for Sustainable Development as well as within Early Childhood Education (ECE). Arjen Wals (2007) claims that when the overall purpose of education is to achieve a more sustainable world, education should be about welcoming different values, questions, and perspectives. A number of questions, though, have been raised on what capabilities are needed to cope with a changing society, characterized by uncertainty and multi-layered conflicts of interest (Lundegård and Wickman 2007). Maxine Greene (1995) emphasizes that flexibility and adjustment to new, unfamiliar circumstances are important when dealing with ecological inequities. These capabilities need to be further nurtured and stretched within educational practices in school and preschool. For this to occur, Greene and Wals (2007) claim that educators ought to create multiple opportunities where children's imagination has the opportunity to flourish. Similar to Greene, Vea Vecchi (2010) stresses the educator's role to support ideas made by children that differ from already established perspectives.

Educational systems that privilege rationality, competition and individual achievement have been criticized by many scholars (Dahlberg, Moss and Pence 2007). For example, Bob Jickling (2009) argues that un-dynamic and rigid educational systems marginalise the space where emotional, aesthetic, and explorative learning might take place. He claims that the ability to challenge current positions requires bold, potential ideas which unfortunately often are dismissed as romantic or naïve. Such ideas could instead be viewed as valued symbols of resistance that can beneficially challenge old, 
fossilised habits and contribute to change (Jickling 2009). This argumentation bears similarities to Liselott Olsson's (2009) writings within the field of ECE on the importance of taking young children's questions as realistic and sensational. Olsson claims that children's wonderings are particularly significant when touching upon science-related subjects that humanity has struggled with through history. For example, questions like: How can we learn to fly? (Olsson 2013). Grounded in Gilles Deleuze's (1994) philosophy, she argues that young children, not yet caught up in a so-called "ortodoxian thinking", have a unique desire for "creative thought" (p. 131). Children's open-mindedness also provides a reason why they often head for imaginative solutions to problems. In her research, she exposes how young learners invent new problems and raise questions when participating in scientific investigations on optical phenomena. A conclusion drawn is the need to take children's questions and concerns into serious consideration in education and research.

Accordingly, when children create meaning there is no obvious dividing line between fact and fiction, sense and nonsense. On the contrary, Kaustuv Roy (2005) implicates teacher's responsibility to draw attention to these connections when the first passage through nonsense might later lead to sense productions. Based on this, a need arises to understand how the process of imagination works, specifically how children anticipate and treat with care something that concerns them related to what they regard as important within a sustainable future.

We have taken the opportunity to empirically investigate the children's esthetical and imaginative ideas and the transitions between nonsense and sense in their activities. Issues concerning imagination have also been touched upon within Early Childhood Education for Sustainability (ECEfS). Sue Elliot and Julie Davis (2009) and Solveig Hägglund and Ingrid Pramling Samuelsson (2009) remind us that young children have the most potential to innovatively contribute to global change over time. Rightfully, they ought to be considered as the most important decision makers of and in the future. Society could provide educational opportunities where all children can participate in open, imaginative inquiry in order to contribute to global change (International Institute for Environment and Development 2010). Or as Lynda O'Gorman and Davis (2013) conclude, "intergenerational equity" (p. 1) can and should be strived for when sustainability is the goal. Thus, research on how to bring forth imagination within teaching and learning involves children's co-construction of ideas and new prototypes that might be useful today and in future.

To sum up, imagination treats familiar objects in new light and thus broadens and deepens human experience. Thus, as tomorrow's environmental challenges are unpredictable, the need to nurture children's imaginations within science education is crucial. This study responds to the complexity of issues concerning sustainability as they are situated within ECE. It explores how children imaginatively wrestle with a problem in which their attachments are at stake (Van Poeck, Goemine and Vandenabeele 2016). Through this process of imagination, connections might be made to biodiversity loss, an intricate feature of the "green" ecological aspect (Payne 2010). Further, it addresses how this process becomes a resource when children are dealing with something they care for that is threatened in their environment.

In this study, our focus is the visible process of imagination on issues perceived by children to be sustainability of animals. 


\section{Previous research on imagination in education}

The following section presents research related to imagination, first treated as an individual capability, then as interwoven in human cooperative processes necessary for sustainability. In addition, research on the so called third space and teachers practicing a listening approach is highlighted.

Some researchers have been troubled with the ontological question of what imagination is and where it is to be located. For example, Kieran Egan (1992) as well as Keiich Takaya (2004) claim that imagination is found in the flexible human mind. Similarly, Egan (2005) argues that the ability to imagine has a significant role when humans are involved in innovation. Other researchers such as Michiel van Eijck and Wolff-Michael Roth (2013) emphasise that through imagination and novelization humans find new ways of acting in the world. Sandri (2013) deepens this discussion in relation to sustainability issues by arguing that the human ability, to envision alternatives, ought to be in focus when learning about sustainability as it helps us in creating innovative solutions to the large-scale challenges we face. Similarly, Kathleen Aikens, Marcia McKenzie, and Philip Vaughter (2016) echo that climate change adaption including socio-economic crisis and the loss of space, requires new imaginative forms of education for sustainability.

A few empirical works have been produced that touch upon imagination particularly within science education. For example, Maria Andrée and Lotta Lager-Nyqvist's (2013) research found that imagination is a vital dimension of science classroom life. A conclusion drawn is that during student's joint explorations imagination enriches and broadens the students' science interests and concerns. Moreover, Chistina Siry and Isabelle Kremer's (2011) research revealed that young children's ideas on science phenomena is fairly sophisticated. In their research, the children's science inquiry is characterized as a nonlinear path where new ideas are collaboratively constructed. Siry and Charles Max (2013) cased children's capabilities as they competently designed and conducted new scientific investigations on solids and liquids by using water and crayons. Their findings revealed that the children sufficiently, through joint actions, conducted science investigations. Another study by Glynne Mackey (2012) on young children's decision-making touches upon sustainability and exposes various ways in which children act for the environment. In this research, imagination had a significant role in the children's meaning making. For example, one child was troubled with the fact that Antarctica's extreme, cold, climate might kill the baby penguins. Through imagination, an innovative, plastic machine was constructed in order to rescue the chicks. Other action-oriented researches on children's inventiveness coupled to science education were conducted by Britt Jakobson and Per-Olof Wickman (2015). When elementary school children in science class were involved in learning about trees and plants, they participated in an activity on rubbing leaves. One girl made a figurative picture, an imaginative assemblage depicting, for example, houses and butterflies. Common to these studies are that they investigate the various functions of aesthetic expression in children's meaning making.

Interest in change and novelty has been brought forth when discussing cultural perspectives in science education. In this context, particularly when striving for a more just and inclusive education where marginalised voices are acknowledged, the concept of third space has received attention. Based on a socio-cultural perspective Kris Gutierrez, Betsy Rymes and Joanne Larson (1995) introduce third space (p. 446) in order to highlight the intrinsic interconnectness of culture, learning and language. Drawing from Edward Soja (1996) and Gutierrez's (2008) theories, Heidi Carlone and Angela Johnson (2012) suggest 
a transformative "third space" (p. 152), where expanding meaning making takes place. The concept is then explained as a culture/discourse emerging when different funds of knowledge hybridize and "bring new forms of science into existence" (p. 155). In earlier work, third space was suggested as a particular place where two normative patterns interacted and where new creative forms of learning could take place (Guattiérrez, Rhymes and Larson 1995). Thus, third space was related to activities in the classroom where terrains/discourses were regarded as separate but became joined in educational practice. Later, a shift towards a more hybrid third space was elaborated on, where different resourses of knowledge and activities/literacies amalgamate. Within this context, the students mutual exploration enhances their equity in science education (Carlone and Johnson 2012) as it allows them to bring personal desires, interests and concerns into the cooperative practice. In relation to this particular study, aiming at discerning which different experiences children use to imagine solutions for animals' welfare, both perspectives concerning place and personal desires are of particular interest.

Young children's voices are still not well represented in research on environmental education and education for sustainability (Stevenson, Brody, Dillon and Wals 2013). Furthermore, children's different anticipation and interests are sometimes elusive and difficult to discover as it requires complete presence and attention of the teacher or researcher (Dahlberg and Moss 2005). Because children's communication often reaches beyond verbal utterances, it also challenges our sensibility for listening to languages other than verbal (Dahlberg, Moss and Pence 2007). Open and careful listening involves questioning the status quo and an engagement with the not-yet known (Davies 2011). However, where ethics are interlaced with listening, critical questions are raised about which voices should be privileged (Vecchi 2010). Greene (1995) emphasizes that the grown-up generation has a responsibility to include the "new comers' voices" (p. 56). With such support, children can reach beyond conventional ways of dealing with the world. However, there is a danger involved if one is too comfortable with the dominant voices (Vecchi 2010). As the concerns and ideas of the disregarded ones are at risk of being overshadowed, the educational challenge is to make space for all children to become "agents for change" (Bigger and Webb 2010, p. 1).

As indicated through this literature review, enhancing the process of imagination in the realms of science and sustainability education is obviously of importance. Nevertheless, the contributions on this area of research are still quite few, and mainly rhetorical. This particular study will scrutinize how children's voices are accentuated within the cooperative act of imagination (expressed as utterances and visible in their drawings), which in turn, paves the way for them to be heard. Hence, this article strives to empirically investigate how imagination as an unscripted process emerges and impacts a given situation. It begins to answer the question of how the children jointly invent new ways of protecting something they cherish in their environment. When we specifically examine the fabrication of how new lines of ideas come into existence, we try to speak of this in accordance with John Dewey's writings on imagination (1934/1980).

\section{A Deweyean approach to imagination}

\section{Imagination as a process}

As outlined earlier, our concern is with how the process of imagination, situated in a cultural and social practice comes into play when children invent, anticipate and explore a 
problem that concerns them. A theoretical perspective is required that emphasizes the significance of the context for children's meaning making and learning that takes imagination into consideration. Instead of framing this work through cognitive theory which reifies activities into mental states (Lundegård and Hamza 2014), we have chosen a pragmatic, action-oriented framework based on John Dewey's work (1934/1980, 1938/ 1997, 1925/1958). Rather than conceptualize imagination as a fixed entity held by a detached individual, or as a romantic, mysterious, chaotic, or irrational property (Garrison 1997), we consider it as an activity in which human beings compose an integral whole within an experience (Dewey 1934/1980). Dewey articulates the significance of taking care of children's imagination within education as a powerful way to reach vital experiences (Dewey 1934/1980). Thus, imagination includes "dissolution of old objects" (Dewey $1925 / 1958$, p. 220) and blending "ideas that can possibly reconstruct the situation" (Garrison 1997, p. 96). The capability of blending has often been described as located in the mind of human beings bestowed by evolution to create new ideas through the combination of older ones (Turner 2014). However, this approach that locates blending in the cognitive domain runs the risk of transforming children's actions into mental abilities (e.g., Lundegård and Hamza 2014). Despite this fact, we consider blending as a useful concept though it helps us describing the visible solutions to problems made by children produced in an imaginational process.

\section{Practical epistemological analysis}

In this study, we have taken Dewey's (1938/1997) framework of experience into consideration. According to this, experiences are continuously transformed through all human encounters within the world. Thus, in new situations that involve action both the subject/ individual and the object/world are transformed. When Dewey and Bentley (1949/1991) delineates experience they employ the term transaction, in order to analytically focus the entire event or process (Lundegård and Wickman 2012). Several researchers have developed research methods based on this transactional approach (e.g., Öhman and Öhman 2013) as it makes it possible to avoid looking for already preconceived definitions, such as individuals with certain mental states, for example, as fixed imaginative properties interacting (Dewey and Bentley 1949/1991). In contexts where transactions are investigated, the analytical distinctions are instead made from the research purpose (Biesta and Burbules 2003). In order to pay attention to the ongoing transactions, this study utilizes a Practical Epistemological Analysis (PEA) (Wickman and Östman 2002), which is developed from a pragmatic framework built on Dewey (1925/1958) and Wittgenstein's (1969) philosophical investigations. PEA is a well-established analytical tool with a carefully developed nomenclature (e.g., Rudsberg and Öhman 2010) used specifically to describe meaning making and learning as on-going changes in human conduct. This study relates to this framework as it specifically analyses how new relations become established as they connect aspects/content from various experiences within children's communication, i.e. how their familiar experiences from everyday life become related and blended into innovative inventions to secure the life for animals they care about. Moreover, while children create meaning and participate in an activity toward a purpose there is always anticipation involved (Dewey 1938/1997), which can be registered in their positive or negative aesthetic judgments and also expressed by, for example, laughter and other outbursts (Jakobson and Wickman 2008)—all visible in their dialogues (Caiman and 
Lundegård 2014). By thoroughly scrutinizing how diverse experiences emerge, dissolve and become blended, this article strives to empirically investigate the process of imagination in accordance with Dewey's articulations. Following preschool children's explorative work by highlighting anticipation expressed in positive or negative aesthetic judgments through three illustrative examples makes this possible.

\section{The aim of the study}

Previous research has broadly put forward areas of content and conditions related to imagination. Here we probe into the entire process of imagination and visualize what blends that come into existence. Inspired by Dewey's pragmatic framework on imagination, the specific aim of this study is to empirically scrutinize how the processes that the children are involved in emerge and develop when investigating sustainability and survival of animals. Following a small group of children in an informal activity makes this possible.

Research questions:

1. Which experiences are used by the children when new imaginative blends come into existence?

2. How are these different blends transformed as the children involve themselves in imagination?

3. In what way are these imaginative outcomes connected to sustainability issues that young learners construct?

\section{Data collections}

In this qualitative research, based on the pragmatic, action oriented approach, pre-school children's imaginational explorations in a science-related context are in focus. These explorations, aligned with (Guattiérrez, Rhymes and Larson 1995) elaboration on third space, takes place "in between" a formal inquiry-based activity and lunchtime, an imagined space of possibility where children are in charge. We make use of data from a larger study (Caiman and Lundegård 2015). This study represents a network between several suburban preschools that are employing a 2-year project where teachers are striving to create opportunities for children to make cooperative explorations and construct their own problems and questions concerning biodiversity. During this project, the teachers continuously reflect on children's meaning-making in regard to the diverse species they encounter. An on-going discussion among the teachers concerns the value of protecting biodiversity, which is one aim of an education toward sustainability (Gaston and Spicer 2013).

The pre-school was visited on nine occasions during 6 weeks. The empirical material from this selected pre-school consists of $9.5 \mathrm{~h}$ of videotape and their accompanying transcripts. The pre-school is located in a large suburb of Sweden, and the children participating in the study are between 4 and 5 years old. The classroom consisted of 20 children and three teachers (two pre-school teachers and an assistant). The data collected consists of photos, children's drawings, pedagogical documentations, and field notes. No personally sensitive data has been collected and the overall purpose and research questions did not exceed the limit of the children's personal integrity. The children, the art workshop/ 
studio teacher (Vecchi 2010), and the teachers at this site had been exploring organisms and creating different ecological systems throughout the project. Following the videotaping, specific moments were located in the data wherein the children jointly invented a problem, lived through a process of imagination, and produced innovative blends such as, a frog-pram.

The specific video material was first viewed as a whole in order to find sequences and critical incidents. Then we continued by discerning those moments with a defined beginning and ending (Flanagan 1954). Third, a selection was made through a careful reviewing, first separately by each author and then jointly deciding what to use when elaborating on the overall purpose. These sequences, presented as vignettes, are transcribed in detail. They are not selected as representative for the project as a whole, but occurred only twice. Thus, they are dealt with as unique, illustrative example of imagination as an outcome and a process. To achieve a richer description and to get a more thorough and detailed analysis in those particular moments, we have also included the children's drawings. In the fourth and final stage, we analysed how the children through communication established new relations to their drawings and each other's utterances. In this way, various experiences from everyday life was blended into resourceful creations designed to protect animals.

\section{Imagination as outcome and process: analysis and results}

In this section, various research vignettes and accompanying drawings will be presented and discussed to answer the research questions. Accordingly, the vignettes identified how children's previous experiences were re-actualized and blended so that something new came into existence. In the analysis, we paid specific attention to when the children anticipated and brought enthusiasm to the situation, as well as to the problem that they created and reconstructed during the process. In this study, the purpose was to investigate children struggling with a problem of their own concern.

In the first example, the children showed the researcher an imaginative outcome (the final artwork), a representation of how they solved a problem concerning animal's hunting skills. The presented blends were established by a few comments and accented by details in the children's drawings.

In the second example, "A process of imagination", we instead approached imagination as an on-going activity and traced how the children made use of different combinations of experiences. The foremost interest was to explore how the process of imagination developed and took shape within practice. Similar to the first example, we highlighted the relations that became established in the process and how those relations contributed to a blending that supported their environmental concern. Therefore, we paid close attention to how the purpose grew and became reconstructed throughout the process.

\section{A snapshot of imagination: A “five-arrowed tongue," a "wiggle-tongue," and a "glue-tongue"}

During several months, the children under study explored various organisms such as cockroaches and woodlice. Meaning was created in different ways surrounding the animal's morphology, physiology, and ecology. Hunting skills, predation, and the relationships between the animals and their environments were examined. A comparison between 


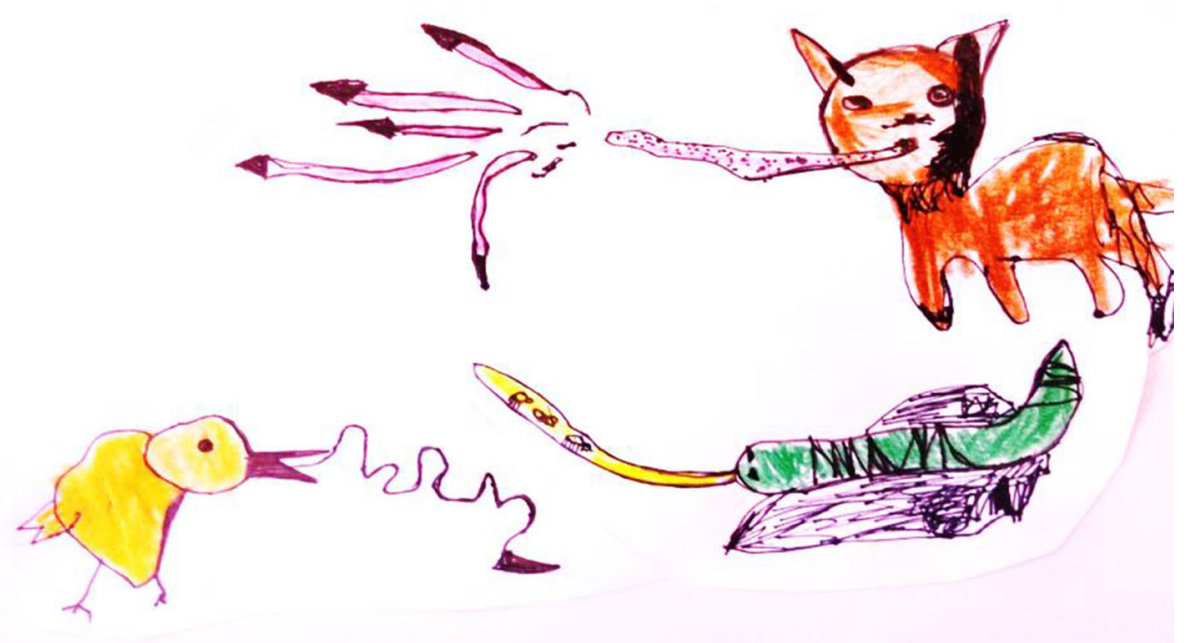

Fig. 1 The children's collage with three blends

human and animal tongues was made where their usage was closely examined. When 5-year-old Helmer stated, "We know everything about normal tongues", he clearly illustrated that it was time to move further from tongues that were anatomically wellknown. Then, along with the other 5-year-olds, he outlined a new direction and anticipated an idea on how to effectively better the animals' hunting skills with the help of prior experiences of, for example, glue. In the collage below, we were able to observe their results where three new blends have emerged. The concepts used in the description below are based on the children's comments.

In the left corner, the children have created an imagination of a common bird with a "wiggle-tongue" (Fig. 1). This bird appeared to be transformed into a creature that effectively catches spiders and mosquitos. In the other corner, the children have placed a long snake equipped with a "yellow tongue with super-glue and three insects". Another larger animal transformed into a hybrid with a "poison tongue that can be changed into a five-arrowed tongue" dominates the picture. The arrows are only released if the creature by perchance encounters a herd of small animals, or as a girl commented: "it catches almost anything". Afterwards, stated by the children during a revisit around the imaginative assemblages in the collage, these imaginative solutions were commented upon as if they were made within a specific purpose related to survival of animals: "animals really do need good tongues... then they can live longer". Through their few utterances the children exposed their interest in the organisms' hunting skills and survival.

To sum up, inspired by the purpose to effectively bettering the animals hunting skills, new imaginative blends emerged in the children's transaction of their everyday life experiences such as glueing and hunting with arrows as well as their knowledge of animal tongues. Here, in the picture (Fig. 1) three blends are sketched out by the children. 


\section{Outcome analysis}

New blends transformed by relations from diverse experiences.

- Common bird-wiggle-tongue

- Long, snake-tongue with super-glue

- Another larger animal-poison tongue, five-arrowed tongue

The imaginative products/blends in the pictures may be captivating, but the course of action, the imaginative process with all diverse choices made by the children, remains nevertheless still invisible. In the second, following example, the process of imagination will be revealed.

\section{A process of imagination: a pram, a tunnel and a trampoline}

\section{The pram}

The 5-year-old children Olle, Noa, and Astrid remain seated at the work station. They have just finished their exploratory research on cockroaches' and frogs' morphology and physiology. The teacher, Sanna, begins to remove their discarded drawing tools as they are on their way to the lunch room. She mutters, "surely, we can help each other to clean up a bit...like we usually do". The children ignore her and suddenly Astrid says, "this is what frogs do. Yes, it is". Then she stands up, puffs up her cheeks many times and becomes redfaced. The boys laugh and, just as Astrid, they begin to puff up their cheeks while giggling throughout. One by one they finish this play and slouch back into their chairs. It is quiet for a few seconds and then quickly Olle says:

"I've seen it on the telly... frogs can carry on their backs..." Noa frowns and says: "What, what do you mean?" Olle continues to explain: "Yeah I have seen it... they can carry frog children if they are tired". Astrid joins in: "We can make carts for them... we'll make prams instead!" Olle shouts and waves with his arms: "Yes that's really good! Prams, we can make them then the frog children can be lazy". Astrid laughs. The children play around for a while. Noa smiles and continues to speak: "And then they can cross the road faster so they won't be run over". Astrid continues excitedly: "Yes, we can make it, we'll do it"! The children draw in silence. Drawing the spokes on the pram's two wheels is an arduous task.

The teacher who has been watching them drawing joins in and says: "Yes, what a good idea you have. The frogs can rest in the prams and they can use these to avoid being run over. What a great idea! You did a really nice picture of it." Noa looks up and smiles. Johan smiles as well and says: "Yes!"

\section{Transactional analysis}

Olle initiates the discussion by establishing a relation to a previous experience from a television program about frogs. With Noa's help he describes how the frogs carry their tired offspring on their backs. Astrid tries an idea that she vivaciously formulates as two suggestions. She imagines that they will create carts, but changes her line of thought and suggests that they instead can make prams for the frog children. In Astrid's immediate encounter with the frogs, her experiences of carts gain new meaning. They can be used for frog children. By the aesthetic utterance "Yes that's really good! ..." Olle expresses 
anticipation upon the situation and adds humorously "...then the frog children can be lazy". Next, Noa articulates a purpose. He reconnects to Astrid's idea and claims that in this manner the frogs will avoid being run over when they cross the road. Astrid agrees and brings anticipation to this idea "Yes, we can make it, we'll do it"! The intensity increases. The teacher recapitulates the whole event and expresses an appreciative aesthetic judgment that underlines the children's proposal, "...What a great idea"!

In the transaction, the children's earlier experiences continuously transform into a new imaginative blend. Now the frogs can both travel and push prams across a dangerous road. Worth being highlighted is that initially, there was no clear purpose announced. However, shortly after the process had begun a problem took shape when Noa established a relation between the prams and the safety of the frogs and their offspring from being run over. Primarily, the children engaged in playful nonsense which later transformed into sense production when the process developed into an imaginative resourceful solution for a problem they had invented along the way (Fig. 2).

New blends transformed by relations from diverse experiences in mutual imagination

- Carts-for them (the frogs)

- Prams-for the lazy frog children

\section{The Tunnel}

Based on the purpose the children previously established together they continue to reconstruct the problem.

Astrid: "Yeah, but we can also make tunnels... perhaps... we can make tunnels that small animals can use... you know tunnels?" The teacher continues: "Another good idea, well done... prams and tunnels, what interesting solutions... then the animals can move freely. Do you want to draw?" Astrid turns to Noa and says: "Yes, and you can do the road Noa. Here". (Astrid points at the middle of the paper) Noa answers quickly: "I'll do that".

Noa and Astrid are drawing. No one speaks.

\section{Transactional analysis}

The children continue to connect their explorative work to the purpose newly introduced by Noa, e.g. to “...cross the road faster so they won't be run over”. When Astrid suggests another solution to this problem she simultaneously expands the aim. By suggesting a use of tunnels under the road, she expresses care and concerns for the "small animals..." as well. The actively listening teacher summarizes the core of the process and participates with several aesthetic judgments: "Another good idea, well done... prams and tunnels, what interesting solutions..." then she asks the children if they would like to draw the idea, which they do.

In this part of the transaction, the children's experiences of tunnels, small animals, roads and cars come together and become re-encoded into a second new blend. The children's previous experiences once again are transformed into something new, produced as an image. 


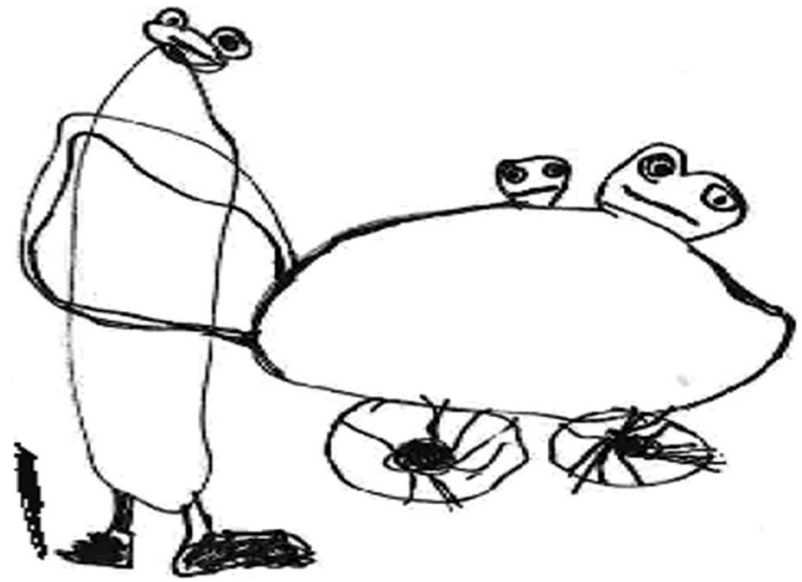

Fig. 2 The children's drawing of two "lazy" frog children pushed in a pram

While the children created a new solution to the problem, to some extent the pronounced aim of the activity was changed. Now, small animals in general and not just frogs could use the tunnels to escape the traffic (Fig. 3).

A new blend transformed by a relation from diverse experiences in mutual imagination

- Tunnels-that small animals can use

\section{The trampoline}

The children continue their imagination.

Astrid: "They need something they can jump on... jump across the dangerous road with all the cars... then the animals can leap over..." The teacher continues:"Could you explain a little bit more?... I don't really understand... Leap over?" Noa says quietly: "Hmm, well... when you bounce and bounce... It can be a trampoline!" and Olle continues: "Ahh... a bit longer and narrow... small animals can leap over the road like that..." Astrid utters: "On the other side...grass and apples... it's probably going to be difficult for an elk to climb up...oh no!, but a fox can... and perhaps ants". Olle continues: "Great... we can draw... we can draw it now..." Teacher: "Sure, do that".

Without saying anything the children leave the table and run off for late lunch. The teacher smiles and shakes her head.

\section{Transactional analysis}

In this last stage of the process, a third solution takes form as Astrid imagines another idea. The animals could instead have "... something they can jump on..." and in that way cross the traffic road safely. The teacher does not fully understand and asks Astrid to develop her idea further "Could you explain a little bit more? ... I don't really understand... Leap over"? Noa continues and imagines how this might work "... when you bounce and bounce..." and in doing so he finds a possible solution"...It can be a trampoline". Olle 


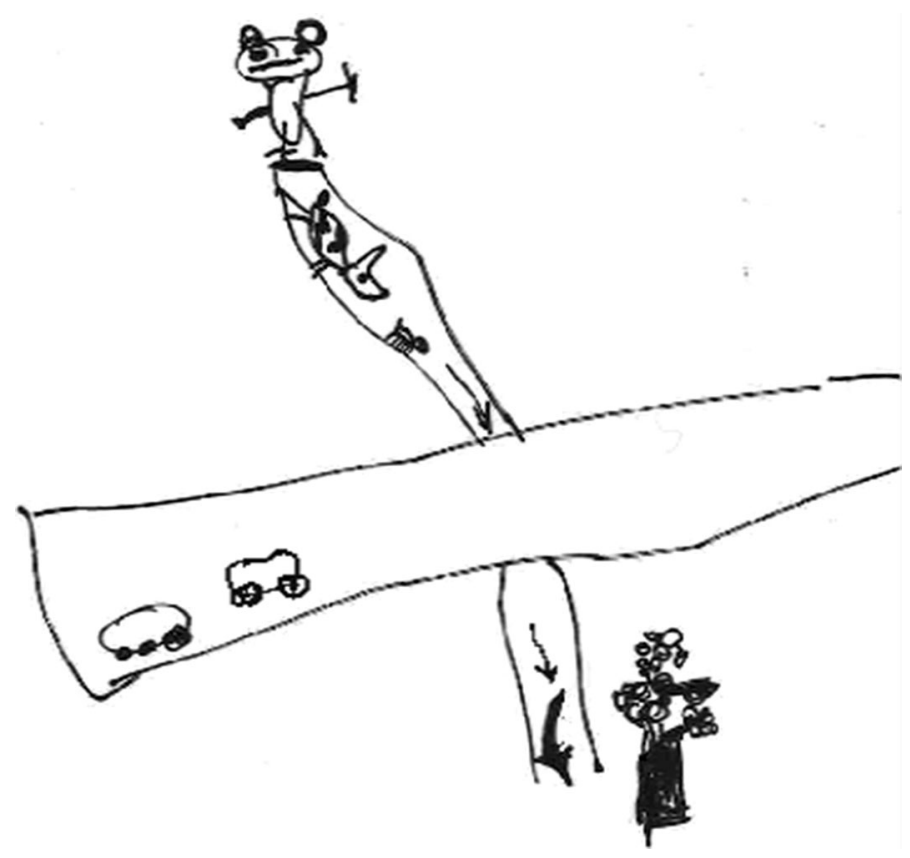

Fig. 3 The drawing of a tunnel under the road. The animals are in a queue

swiftly carries on and develops the idea even further. The trampoline, first expressed as a garden trampoline, eventually transforms during the process into an appropriate pool trampoline. Astrid imagines the other side of the road where the animals are headed filled with "grass and apples". The children still pay attention to the small animals but include the larger ones, a fox and an elk as well. They explore each animal's different possibilities for using the narrow, long trampoline, and worries are expressed around the table regarding the over-sized elk that will not manage to climb onto the trampoline. This trouble remains unsolved. Olle instead aesthetically assessed the whole idea as "great" by enthusiastically suggests drawing the solution. The teacher supports the proposal and the drawing begins.

Towards the end of the process, a diverse repertoire of the children's previous experiences are continuously made use of in a most creative way. The new blend develops in the children's experience of a garden trampoline, a pool trampoline, small and big animals, the road with all the cars and the temptations such as apples on the other green-sided road. Once again, the experiences continuously transform into a third new blend produced as a drawing. The children expand the purpose even further when the activity reaches for fulfilment. Now both small and large animals can cross the road safely with the use of a specially designed trampoline (Fig. 4).

New blends transformed by relations from diverse experiences in mutual process of imagination

- Something the animals can jump on-across the dangerous road

- It can be a trampoline-the animals can leap over

- A bit longer and narrow (pool-trampoline)—small animals can leap over the road 

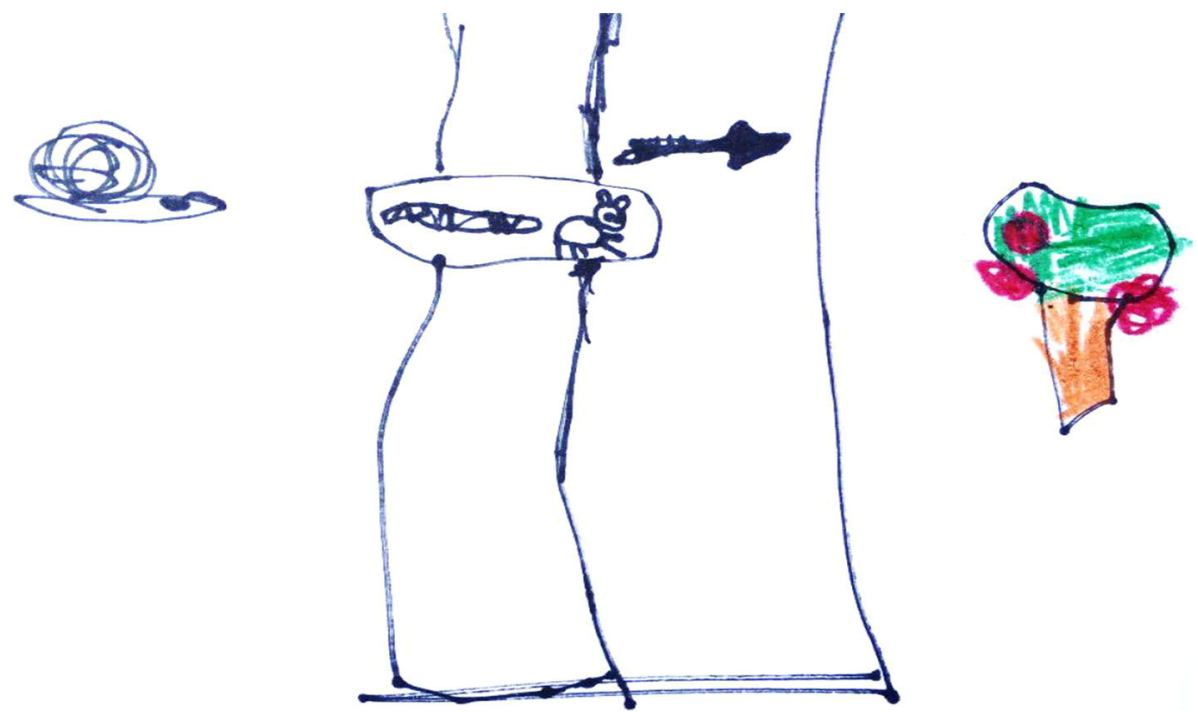

Fig. 4 The drawing of a trampoline, animals and a green tree with red apples. (Color figure online)

\section{Summary}

The first example, "A snapshot of imagination", is created within a science-related activity at the pre-school. The children comment upon the new blends (outcome) in the collage (Fig. 1). The three animals are imaginative blends that have been invented in order to better the animals' hunting skills. The children's drawing revealed that they have utilized different every day life experiences such as glueing and hunting with arrows (research question 1) but the situated, communicative process, in which the children construe various relations, still remain unobservable.

In the second example, imagination becomes visible when addressing it in situ. While the children lived through the entire event, three new and unusual solutions (outcomes) to the problem with the dangerous and busy road were invented. Carts (for the frogs), a tunnel (for small animals) and a pool trampoline (that both small and bigger animals could use) have been transformed into blended existence (research question 2). In this process, the children make use of and transform earlier experiences. Sometimes an immediate experience has an obvious reference, for example, a television program of frogs that a child refers to, sometimes it is much more difficult to trace the origin of a particular experience. However, a diverse range of experiences with frogs, ants, a fox, an elk, and different, specialised trampolines and particular carts gain meaning as the imagination progresses (research question 1). These experiences became valued resources as they nursed and fertilized the process even further. Moreover, and continuously, the children's rich experiences are transformed into unique, unconventional images. Instead of viewing imagination as a generic ability/competence the imaginational process is something that comes into existence through the on-going transaction. 


\section{Purpose by transactions}

Initially, the children announced no specific purpose. Playfully, and with what seemingly appears as nonsense they explored and constructed a more exciting way for frogs to transport their offspring. During the whole event, the purpose, related to adaptions of animals, was reconstructed and expanded (research question 3). However, by "one stroke of the magic wand of imagination" (Dewey 1913, p. 78) the children pointed out a direction and articulated a purpose; new solutions to the problem that simultaneously made sense of the situation. From the first sequence where the purpose was to create prawns that protected the animals from "avoid being run over", the later solutions became a tunnel and eventually a trampoline which both small as well as larger animals could use. Finally, the overall purpose (which became clearly visible in the children's pictures) provided a safe crossing for all kind of animals. A purpose that could be regarded as an empirical answer to how attachments at stake (Van Poeck, Goemine and Vandenabeele 2016) might look like in early childhood when focusing science and sustainability related concerns.

\section{Discussion}

\section{Embracing children's potentiality to imagine}

In the twenty-first century, problem solving is essential for the growing generation, not least when facing unstructured and multi-layered problems (Churchman 1967). A society characterised by varying degrees of uncertainty raises questions within education on what competences and skills young learners need to develop further (Greene 1995). In this article, we engage in this debate by highlighting the value of embracing imagination as a powerful way of dealing with sustainability related problems as well as inventing new ones. This implies that teachers and researchers have to more carefully listen to and take care of all children's imagination within educational practices. Consequently, activities where children's imaginational ideas on how to bring about sustainable change are taken into account (Sandri 2013) are needed. This study has specifically focused on the potential of children's imagination which involves a desire to explore the not-yet known as well as reach beyond conventional ways of acting. Further, our overall aim has been to scrutinize imagination as a cooperatively evoked process situated in a pre-school context. In line with Dewey's assertion that imagination is dependent on and situated in context, we have approached imagination as contingent and progressing in on-going transactions (Dewey and Bentley 1949/1991).

We found that imagination has a great significance when children create, extend and provide different solutions to a problem. In the second example, we step by step unfolded how the process emerged and developed. From rich and diverse experiences, the children created new imaginative solutions by allowing new blends to come into existence. Instantly, prams became a solution to transport lazy frog children. Hence, more thoroughly, a tunnel under the traffic road was invented as well as a beneficial trampoline designed for animals to leap over a dangerous road. By a 'collaborative endeavour' (Siry and Max 2013, p. 900), the children competently developed experimental designs related to science and sustainable issues and as a consequence, the whole situation was expanded (Dewey 1938/ 1997). This study could be viewed as an empirical answer to theories on third space, i.e. places where new creative forms of learning could take place (Guattiérrez, Rhymes and 
Larson 1995) and where the student's different funds of knowledge in science practice are allowed to be mixed (Carlone and Johnson 2012). Through everyday experiences (a pram, a tunnel and a trampoline) their imagination was further fertilized and most of the animals, except for the large elk were saved.

Realized in this study was how the children through the process defined a problem and mapped out a direction. Interestingly, the problem and the actual purpose of the activity were not pronounced in the very beginning. Instead, what at the beginning looked as "nonsense" gradually emerged when the children faced their own blends and thereby created anticipation. The children's imagination became framed by a problem that appeared as important to them.

Our results showed that the children's imagination was related to how the process took form and progressed as well as to the blends the children were creating (e.g. Turner 2014). The results can be viewed as an empirical affirmation that science and education for sustainability is something in-the-making (van Eijck and Roth 2013). Sometimes it might be difficult to know if a particular line of children's imagination has a substantial potential or not. As a matter of fact, a road tunnel is already a real solution invented and implemented to bridge an actual problem, e.g. to save and protect endangered species like frogs against heavy traffic.

\section{Implications for educators}

Iris Duhn (2012) advocates the need of developing what she calls a new 'community of empathy' including aspects of ethics such as listening and caring for others. This demands the grown-ups to fine-tune their listening and to embrace all children's potentials (Vecchi 2010). In this study, the participating teacher performed a listening approach (Dahlberg and Moss 2005) in two ways. First, she solely used positive aesthetic judgments and secondly, continuously recapitulated the children's process in order to reflect and move further. An educational implication drawn is that if one purpose of education is to support children's imaginative flow encouraging them through the whole process seems imperative. The outcomes of the children's imaginations might strike as naïve or romantic, but the children's ideas could also be viewed as acts of resistance turned into constructive solutions (Jickling 2009). Through the illustrated sequence of events, the children formulated a resistance concerning animal's vulnerability to car traffic and anticipated care and concern for the animal's wellbeing (question 3).

This work has demonstrated that imagination might be a powerful aspect in meaning making and learning within pre-school education. It has a great significance when multicomplex problems related to science and sustainability are addressed. When young children are given the opportunity to act both as learners and experts (Siry and Max 2013), they can offer help for humanity extending beyond conventional ways of acting.

Open Access This article is distributed under the terms of the Creative Commons Attribution 4.0 International License (http://creativecommons.org/licenses/by/4.0/), which permits unrestricted use, distribution, and reproduction in any medium, provided you give appropriate credit to the original author(s) and the source, provide a link to the Creative Commons license, and indicate if changes were made. 


\section{References}

Aikens, K., McKenzie, M., \& Philip Vaughter, P. (2016). Environmental and sustainability education policy research: A systematic review of methodological and thematic trends. Environmental Education Research, 22, 333-359. doi:10.1080/13504622.2015.1135418.

Andrée, M., \& Lager-Nyqvist, L. (2013). Spontaneous play and imagination in everyday science classroom practice. Research in Science Education, 43, 1735-1750. doi:10.1007/s11165-012-9333-y.

Biesta, G., \& Burbules, N. C. (2003). Pragmatism and educational research. Lanham, MD: Rowman and Littlefield.

Bigger, S., \& Webb, J. (2010). Developing environmental agency and engagement through young people's fiction. Environmental Education Research, 16, 401-414. doi:10.1080/13504621003613145.

Blenkinsop, S., \& Egan, K. (2009). Three big ideas and environmental education. In M. Mckenzie, P. Hart, H. Bai, \& B. Jickling (Eds.), Fields of green: Restorying culture, environment, and education (pp. 85-93). Cresskill, NJ: Hampton Press.

Caiman, C., \& Lundegård, I. (2014). Pre-school children's agency in learning for sustainable development. Environmental Education Research, 20, 437-459. doi:10.1080/13504622.2013.812722.

Caiman, C. \& Lundegård, I. (2015). Barns meningsskapande i ett projekt om biologisk mångfald och ekologi Children's meaning making in biodiversity and ecology. Nordic Studies in Science Education, 11(1), 73-87. https://www.journals.uio.no/index.php/nordina.

Carlone, H., \& Johnson, A. (2012). Unpacking 'culture' in cultural studies of science education: Cultural difference versus cultural production. Ethnography and Education, 7, 151-173. doi:10.1080/17457823. 2012.693691.

Churchman, C. W. (1967). Wicked problems. Management Science, 14, 141-142. doi:10.1287/mnsc.14.4. B141.

Dahlberg, G., \& Moss, P. (2005). Ethics and politics in early childhood education. Oxfordshire: RoutledgeFalmer.

Dahlberg, G., Moss, P., \& Pence, A. R. (2007). Beyond quality in early childhood education and care: Languages of evaluation (2nd ed.). London: Routledge.

Davies, B. (2011). Opening listening: Creative evolution in early childhood settings. International Journal of Early Childhood, 3, 119-132. doi:10.1007/s13158-011-0030-1.

Davis, J. M. (Ed.). (2010). Young children and the environment: Early education for sustainability. Cambridge: Cambridge University Press.

Deleuze, G. (1994). Difference and repetition. Columbia: University Press.

Dewey, J. (1913). Interest and effort in education. Boston, MA: Houghton Mifflin.

Dewey, J. (1925/1958). Experience and nature. New York, NY: Dover.

Dewey, J. (1934/1980). Art as experience. New York, NY: Perigee Books.

Dewey, J. (1938/1997). Experience and education. New York, NY: Touchstone.

Dewey, J., \& Bentley, A. F. (1949/1991). Knowing and the known. In J. A. Boydston (Ed.), The Later works, 1925-1953 (Vol. 16: 1949-1952, pp. 1-294). Carbondale, IL: Southern Illinois University Press.

Duhn, I. (2012). Making 'place' for ecological sustainability in early childhood education. Environmental Education Research, 18, 19-29. doi:10.1080/13504622.2011.572162.

Editorial board of IJDCI. (2013). Perspectives on design creativity and innovation research. International Journal of Design Creativity and Innovation, 1, 1-42. doi:10.1080/21650349.2013.754657.

Egan, K. (1992). Imagination in teaching and learning: The middle school years. Chicago, IL: University of Chicago Press.

Egan, K. (2005). An imaginative approach to teaching. San Francisco, CA: Jossey-Bass.

Elliot, S., \& Davis, J. (2009). Exploring the resistance: An Australian perspective on education for sustainability in early childhood. International Journal of Early Childhood, 41, 65-77. doi:10.1007/ BF03168879.

Flanagan, J. C. (1954). The critical incident technique. Psychological Bulletin, 51, 327-359. doi:10.1037/ h0061470.

Garrison, J. W. (1997). Dewey and eros: Wisdom and desire in the art of teaching. New York, NY: Teachers College Press.

Gaston, K. J., \& Spicer, J. I. (2013). Biodiversity: An introduction. London: Wiley.

Greene, M. (1995). Releasing the imagination: Essays on education, the arts, and social change. San Francisco, CA: Jossey-Bass.

Gutierrez, K. D. (2008). Developing a sociocritical literacy in the third space. Reading Research Quarterly, 43, 148-164. doi:10.1598/RRQ.43.2.3. 
Gutierrez, K., Rymes, B., \& Larson, J. (1995). Script, counter- script, and underlife in the classroom: James Brown versus Brown v. Board of Education. Harvard Educational Review, 65, 445-471. doi:10.17763/ haer.65.3.r16146n25h4mh384.

Hägglund, S., \& Pramling Samuelsson, I. (2009). Early childhood and education for sustainable development and citizenship. International Journal of Early Childhood, 41, 49-63. doi:10.1007/BF03168875.

Harvey, M., \& Pilgrim, S. (2011). The new competition for land: Food, energy and climate change. Food Policy, 36, 40-51. doi:10.1016/j.foodpol.2010.11.009.

International Institute for Environment and Development. (2010). Tackling wicked problems [Elektronisk resurs]: Through the transdisciplinary imagination. London: Earthscan.

Jakobson, B., \& Wickman, P.-O. (2008). The roles of aesthetic experience in elementary school science. Research in Science Education, 38, 45-65. doi:10.1007/s11165-007-9039-8.

Jakobson, B., \& Wickman, P.-O. (2015). What difference does art make in science? A comparative study of meaning making at elementary school. Interchange, 46, 323-343. doi:10.1007/s10780-015-9262-6.

Jickling, B. (2009). Sitting on an old grey stone: Meditations on emotional understanding. In M. Mckenzie, P. Hart, H. Bai, \& B. Jickling (Eds.), Fields of green: Restorying culture, environment, and education (pp. 163-173). Cresskill, NJ: Hampton Press.

Lundegård, I., \& Hamza, K. (2014). Putting the cart before the horse: The creation of essences out of processes in science education research. Science Education, 98, 127-142. doi:10.1002/sce.21086.

Lundegård, I., \& Wickman, P.-O. (2007). Conflicts of interest: An indispensable element of education for sustainable development. Environmental Education Research, 13, 1-15. doi:10.1080/ 13504620601122566.

Lundegård, I., \& Wickman, P.-O. (2012). It takes two to tango: Studying how students constitute political subjects in discourses on sustainable development. Environmental Education Research, 18, 153-169. doi:10.1080/13504622.2011.590895.

Mackey, G. (2012). To know, to decide, to act: The young child's right to participate in action for the environment. Environmental Education Research, 18, 473-484. doi:10.1080/13504622.2011.634494.

O'Gorman, L., \& Davis, J. (2013). Ecological footprinting: Its potential as a tool for change in preservice teacher education. Environmental Education Research, 19, 779-791. doi:10.1080/13504622.2012. 749979.

Öhman, J., \& Öhman, M. (2013). Participatory approach in practice: An analysis of student discussions about climate change. Environmental Education Research, 19, 324-341. doi:10.1080/13504622.2012. 695012.

Olsson, L. M. (2009). Movement and experimentation in young children's learning: Deleuze and Guattari in early childhood education. London: Routledge/Taylor and Francis Ltd.

Olsson, L. M. (2013). Taking children's questions seriously: The need for creative thought. Global Studies of Childhood, 3, 230-253. doi:10.2304/gsch.2013.3.3.230.

Payne, P. (2010). Moral spaces, the struggle for an intergenerational environmental ethics and the social ecology of families: An 'other' form of environmental education. Environmental Education Research, 16, 209-231. doi:10.1080/13504620903580545.

Roy, K. (2005). On sense and nonsense: Looking beyond the literacy wars. Journal of Philosophy of Education, 39, 99-111. doi:10.1111/j.0309-8249.2005.00422.x.

Rudsberg, K., \& Öhman, J. (2010). Pluralism in practice-Experiences from Swedish evaluation, school development and research. Environmental Education Research, 16, 95-111. doi:10.1080/ 13504620903504073.

Sandri, O. J. (2013). Exploring the role and value of creativity in education for sustainability. Environmental Education Research, 19, 765-778. doi:10.1080/13504622.2012.749978.

Sauvé, L. (2009). Being here together. In M. McKenzie, P. Hart, H. Bai \& B. Jickling (Eds.), Fields of green: restorying culture, environment, and education (pp. 325-335). Creskill, NJ: Hampton Press.

Siry, C., \& Kremer, I. (2011). Children explain the rainbow: Using young children's ideas to guide science curricula. Journal of Science Education and Technology, 20, 643-655. doi:10.1007/s10956-011-93205 .

Siry, C., \& Max, C. (2013). The collective construction of a science unit: Framing curricula as emergent from kindergarteners' wonderings. Science Education, 97, 878-902. doi:10.1002/sce.21076.

Soja, E. (1996). Journeys to Los Angeles and other real-and-imagined places. Malden, MA: Blackwell.

Stevenson, R. B., Brody, M., Dillon, J., \& Wals, A. E. J. (Eds.). (2013). International handbook of research on environmental education. New York, NY: The American Educational Research Association and Routledge.

Takaya, K. (2004). On the connections between imagination and education: Philosophical and pedagogical perspectives. Doctoral dissertation, Simon Fraser University. 
Turner, M. (2014). The origin of ideas: Blending, creativity, and the human spark. Oxford: Oxford University Press.

van Eijck, M., \& Roth, W. (2013). Imagination of science in education: From Epics to Novelization [Elektronisk resurs]. Dordrecht, Netherlands: Springer.

Van Poeck, K., Goeminne, G., \& Vandenabeele, J. (2016). Revisiting the democratic paradox of environmental and sustainability education: Sustainability issues as matters of concern. Environmental Education Research, 22, 806-826. doi:10.1080/13504622.2014.966659.

Vecchi, V. (2010). Art and creativity in Reggio Emilia: Exploring the role and potential of ateliers in early childhood education. London: Routledge.

Wals, A. E. J. (2007). Creating networks of conversations. In A. E. J. Wals (Ed.), Social learning towards a sustainable world: Principles, perspectives, and praxis (pp. 497-506). Wageningen: Wageningen Academic Publishers.

Weber, E. P., \& Khademian, A. M. (2008). Wicked problems, knowledge challenges, and collaborative capacity builders in network settings. Public Administration Review, 68, 334-349. doi:10.1111/j.15406210.2007.00866.x.

Wickman, P.-O., \& Östman, L. (2002). Learning as a discourse change: A sociocultural mechanism. Science Education, 86, 601-623. doi:10.1002/sce.10036.

Wittgenstein, L. (1969). On certainty. Oxford: Blackwell.

Cecilia Caiman is a researcher at the Department of Mathematics and Science Education, Stockholm University. She is a lecturer in Early Childhood Education as well as in Science Education. Her research focus is on young children's meaning making processes in science and sustainable development.

Iann Lundegård is a senior lecturer in science education at the Department of Mathematics and Science Education. His research interest is students' deliberations and meaning making on sustainable development. He educates teachers and teacher students in science education and education for sustainable development and has written several text books in the field of environmental education. 